Journal for ImmunoTherapy of Cancer

\title{
The Society for Immunotherapy of Cancer perspective on regulation of interleukin-6 signaling in COVID-19- related systemic inflammatory response
}

\author{
Fernanda I Arnaldez, ${ }^{1}$ Steven J O'Day, ${ }^{2,3}$ Charles G Drake, ${ }^{4}$ Bernard A Fox, ${ }^{5}$ \\ Bingqing Fu, ${ }^{6}$ Walter J Urba, ${ }^{5}$ Vincenzo Montesarchio, ${ }^{7}$ Jeffrey S Weber, ${ }^{8}$ \\ Haiming Wei, ${ }^{6}$ Jon M Wigginton, ${ }^{9}$ Paolo Antonio Ascierto (D) 10
}

To cite: Arnaldez FI, O'Day SJ, Drake CG, et al. The Society for Immunotherapy of Cancer perspective on regulation of interleukin-6 signaling in COVID-19-related systemic inflammatory response. Journal for ImmunoTherapy of Cancer 2020;8:e000930. doi:10.1136/ jitc-2020-000930

- Additional material is published online only. To view, please visit the journal online (http://dx.doi.org/10.1136/jitc2020-000930).

Accepted 15 April 2020
Check for updates

(C) Author(s) (or their employer(s)) 2020. Re-use permitted under CC BY-NC. No commercial re-use. See rights and permissions. Published by BMJ.

For numbered affiliations see end of article.

Correspondence to Dr Paolo Antonio Ascierto; paolo.ascierto@gmail.com

\section{ABSTRACT}

The pandemic caused by the novel coronavirus SARS-CoV-2 has placed an unprecedented burden on healthcare systems around the world. In patients who experience severe disease, acute respiratory distress is often accompanied by a pathological immune reaction, sometimes referred to as 'cytokine storm'. One hallmark feature of the profound inflammatory state seen in patients with COVID-19 who succumb to pneumonia and hypoxia is marked elevation of serum cytokines, especially interferon gamma, tumor necrosis factor alpha, interleukin 17 (IL-17), interleukin 8 (IL-8) and interleukin 6 (IL-6). Initial experience from the outbreaks in Italy, China and the USA has anecdotally demonstrated improved outcomes for critically ill patients with COVID-19 with the administration of cytokine-modulatory therapies, especially anti-IL-6 agents. Although ongoing trials are investigating anti-IL-6 therapies, access to these therapies is a concern, especially as the numbers of cases worldwide continue to climb. An immunology-informed approach may help identify alternative agents to modulate the pathological inflammation seen in patients with COVID-19. Drawing on extensive experience administering these and other immune-modulating therapies, the Society for Immunotherapy of Cancer offers this perspective on potential alternatives to anti-IL-6 that may also warrant consideration for management of the systemic inflammatory response and pulmonary compromise that can be seen in patients with severe COVID-19.

\section{INTRODUCTION}

Coronaviruses are a family of enveloped, positive sense, single-strand RNA viruses that infect mammals and birds. In humans, coronavirus infections typically cause mild respiratory disease, including seasonal colds, yet some members of the family can be highly virulent. In December 2019, a novel coronavirus, SARS-CoV-2, structurally related to the virus that causes severe acute respiratory syndrome (SARS) and Middle East respiratory syndrome (MERS), was identified in Wuhan, China. Its efficient transmission $\left(\mathrm{R}_{0}\right.$ of 2.2$)$ facilitated its spread across the globe, with the first detected case in the USA reported on January 19, 2020. ${ }^{1}$ On March 11, 2020, WHO declared the outbreak a pandemic. ${ }^{2}$

The ongoing COVID-19 outbreak is challenging every aspect of daily life, including the implementation of public health policy, the nature of social interactions, adaptation of the workforce to a 'new normal' and the medical research and clinical care infrastructure, including the care for oncology patients. Economic forecasts are concerning, and a global financial crisis is anticipated. Mathematical modeling based on available data shows that in the face of rapid geographical spread and a high case-fatality ratio, even the most advanced healthcare systems are very likely to be overwhelmed in the coming weeks and months. ${ }^{3}$ It will be critical to identify therapies with low barriers to rapid clinical deployment.

It is becoming apparent that in some patients, severe COVID-19 disease occurs, and is accompanied by a fulminant and damaging immune reaction, sometimes called the "cytokine storm', characterized by pronounced infiltration of macrophages and monocytes into the alveolae, a pro-inflammatory T-helper 17 (Th17) response, and elevated levels of inflammatory cytokines, particularly IL-6, IL-1 $\beta$, IL-8, interferon gamma (IFN $\gamma$ ) and tumor necrosis factor alpha $(\mathrm{TNF} \alpha){ }^{4-7}$ This pro-inflammatory cytokine profile has been with poor prognosis and severe lung pathology characterized by interstitial mononuclear inflammatory infiltrates, diffuse alveolar damage, hyaline membrane formation and pulmonary edema. ${ }^{8-10}$

As the oncology community rallies behind our colleagues in intensive care, internal medicine, emergency medicine and 
infectious disease, the immunotherapy field is poised to offer insights into the application of immune-modulatory therapies. Modulation of IL-6, in particular, which has emerged as a potentially promising option for COVID19-related acute respiratory distress syndrome (ARDS), is used for the treatment of some rheumatological disorders, ${ }^{11}$ and has become a mainstay in recent years in the management of cytokine release syndrome (CRS) after chimeric antigen receptor (CAR) T cell therapy for hematological malignancies. ${ }^{12-14}$ Although the cytokine levels observed in patients with COVID-19 experiencing ARDS are much lower than those seen in CRS after delivery of CAR Tcell therapies and CD3-based bispecific Tcell engagers, the cancer immunotherapy community's experience in using the IL-6 receptor antagonists to modulate severe inflammatory pathology in the setting of CRS may prove to be useful in identifying therapies that could be of use in this setting.

Healthcare and research organizations continue to aggressively pursue development of a vaccines and effective therapeutic strategies to attenuate the burden of SAR-CoV-2 (including antimalarial, antimicrobial and directed antiviral agents as well as convalescent serum from patients who have cleared virus and recovered) and to support patients through the severe inflammatory response and pulmonary complications that can frequently occur. The aim of this analysis is to describe available strategies that could alleviate the burden on the healthcare system with a specific emphasis on therapeutics that could block or modulate the systemic inflammatory response and pulmonary complications caused by COVID-19, in particular, IL-6, IL-1 and TNF $\alpha$ pathways. ${ }^{15}$

\section{RATIONALE FOR TARGETING IL-6}

SARS-CoV-2 causes the emergent respiratory disease called COVID-19. One of the challenging aspects in management of the infection is that different presentations have been identified ${ }^{16}$ :

- Asymptomatic carrier state

- Mild respiratory symptoms, not requiring hospitalization

- Recovered and re-examined positive for SARS-CoV-2 nucleic acid after discharge

- Acute respiratory disease: respiratory presentation (fever, cough, dyspnea), without radiological evidence of a parenchymal process. Additional symptoms may include myalgias, headache, sore throat, anosmia, chills, diarrhea, nausea and vomiting.

- Severe respiratory disease: pneumonia, often bilateral, which can progress in severity ultimately requiring mechanical ventilation and intensive care management. While ARDS is the common feature in patients with severe disease, other manifestations have been described, such as acute cardiac injury, acute kidney injury, coagulopathy and shock. ${ }^{17}$

- Lethal infection: the case-fatality rate has been reported from $0.1 \%$ to $2 \%$, although complete epidemiological analysis is ongoing worldwide and facing the challenge of testing availability. Death is typically due to massive alveolar damage and irreversible respiratory failure. ${ }^{18}$

Almost $75 \%$ of patients with COVID-19 acute respiratory disease present with abnormal findings on chest CT scans. Ground-glass opacities are the most common finding, reported in as many as $60 \%$ of patients. Other findings include patchy infiltrates, and interstitial lung disease, although some patients present with minimal imaging abnormalities. 571719

Pathological findings resemble those seen in SARS and MERS: edema, proteinaceous exudates, focal reactive pneumocyte type II hyperplasia, patchy cellular inflammation and multinucleated giant cells. ${ }^{9}$ Notably, neutrophil infiltration is not significant. ${ }^{20}$

Elevated $\mathrm{C}$ reactive protein (CRP) and elevated aspartate transaminase are common in patients with COVID-19 and reports from Hubei province in China indicate that severe cases are associated with elevated levels of inflammatory markers including serum d-dimer, ferritin and lactate dehydrogenase. ${ }^{21}$ The cytokine profile of severe COVID-19 disease is characterized by elevated IL-2, IL-6, IL-7, IL-8, granulocyte-colony stimulating factor, IL-17, $\mathrm{TNF} \alpha$ and other markers that indicate systemic inflammatory response, ${ }^{22}$ similar to what has been described in macrophage activation syndrome (MAS) or in hemophagocytic lymphohistiocytosis (HLH). ${ }^{23}{ }^{24}$ Moreover, a retrospective multicenter study of 150 patients performed from Wuhan, China suggested that among other clinical parameters, CRP and IL-6 levels can be predictors of mortality. Among 68 patients who died, median IL-6 level was $11.4 \mathrm{ng} / \mathrm{mL}$ as opposed to $6.8 \mathrm{ng} /$ $\mathrm{mL}$ in those 82 who survived $(\mathrm{p}<0.001) .{ }^{25}$ Additionally, an elevated neutrophil-to-leukocyte ratio was also predictive of poor prognosis.

In the USA, anticipated shortages of key resources including intensive care unit (ICU) beds and mechanical ventilators has led to the implementation of social distancing measures to avoid overloading a medical system that is not prepared to care for an overwhelming number of affected individuals. ${ }^{26}$ While a concerted effort to increase and coordinate the supply of personal protective equipment for healthcare workers as well as mechanical ventilators for patient care is clearly needed, ${ }^{27}$ a complementary approach to decrease the number of patients with severe disease, and/or decrease the time required in the ICU on a ventilator is important as well.

Based on emerging information as centers gain more experience treating SARS-CoV-2-infected patients, modulating or inhibiting the IL-6 signaling pathway to mitigate the inflammatory response related to COVID-19 is an attractive idea. ${ }^{15}$ There is a successful precedent for this strategy, as it is almost routinely considered in patients receiving $\mathrm{T}$ cell engaging therapies, such as CAR $\mathrm{T}$ cells or blinatumomab. In these contexts, IL-6 levels peak at the time of maximal $\mathrm{T}$ cell proliferation and patients may develop a CRS that can be quite severe and even 
life-threatening. ${ }^{14}$ Administration of IL-6 blocking agents such as tocilizumab and siltuximab has been shown to be effective in reversing CRS in these patients. ${ }^{28-30}$ Tocilizumab was approved by the Food and Drug Administration (FDA) for the treatment of CRS secondary to CAR T cell therapy in $2017,{ }^{13}$ and incorporated into the risk evaluation and mitigation strategies for the approved CAR T cell therapy products, tisagenlecleucel and axicabtagene ciloleucel.

A word of caution should be exercised in extrapolating the adoptive cell transfer experience using IL-6 inhibition to COVID-19, as formal comparative analysis of the levels of pro-inflammatory cytokines in both situations has not yet been performed. Initial data from the COVID-19 pandemic indicate that cytokine levels are far lower in the context of SARS-CoV-2 infection than seen in CRS. ${ }^{25} 31$

A 21-patient observational study recently performed in China supports the use of tocilizumab to avoid rapid clinical deterioration of individuals with severe pneumonitis and pulmonary complications. ${ }^{32}$ Anecdotal cases reported in Italy ${ }^{33}$ also point that tocilizumab may be clinically active in decreasing the magnitude of the inflammatory response associated with COVID-19, with rapid improvements observed in critically ill patients, even those requiring mechanical ventilation. On March 19, 2020, the Italian Medicines Agency announced the launch of TOCIVID-19, an independent phase II study to evaluate the efficacy and safety of tocilizumab in the treatment of pneumonia during COVID-19. Accrual of 330 patients was reached within 24 hours. In the USA, a randomized, double-blind, placebo-controlled phase III clinical trial has recently been approved by the US FDA to evaluate the efficacy of tocilizumab plus standard of care in hospitalized adult patients with severe COVID-19 pneumonia (NCT04320615). A randomized, placebo-controlled phase II/III study evaluating the efficacy of low-dose and high-dose sarilumab, another IL-6-modulating therapy in hospitalized patients with COVID-19 against placebo is also ongoing (NCT04315298).

Multiple doses of tocilizumab may be necessary for maximal benefit. In the Chinese study protocol, patients received $400 \mathrm{mg}$ once through an intravenous drip up to a maximum of $800 \mathrm{mg}$ with an optimal dose of $8 \mathrm{mg} / \mathrm{kg}$ body weight. In cases of fever within 12 hours after the first administration, an additional dose of up to the same amount as the first would be given, with two doses as the cumulative upper limit. The protocol for the Italian trial, calls for doses comparable to those commonly used for the management of CRS, namely, $8 \mathrm{mg} / \mathrm{kg}$ (up to a maximum of $800 \mathrm{mg}$ per dose), with a second administration of the same dose given after 12 hours if respiratory function has not recovered, at discretion of the investigator. In preliminary reports from Italy, meaningful effects have also been observed with the subcutaneous formulation of tocilizumab.

A key lesson learned from the experience of treating about 500 severe or critical patients in China is the necessity of starting tocilizumab therapy as soon as possible, ideally before symptoms start to rapidly deteriorate at the onset of the cytokine storm. It is critical to observe high-risk cases, patients with persistent fever, diffuse lung opacities on CT scans and elevated serum CRP and IL-6 (if cytokine measurements are available). Because the condition can quickly change from mild to severe, early intervention should be strongly considered.

While establishing new indications for an agent generally requires evaluation in a rigorous, often randomized clinical trial, the massive impact of this pandemic, and the lack of any existing standard-of-care might provide appropriate context to consider off-label use of IL-6 inhibition for severely ill patients affected by COVID-19. China's National Health Commission has recently issued updated treatment guidelines that include the use of tocilizumab in patients with severe disease. ${ }^{34}$

The FDA is closely monitoring the medical product supply chain, ${ }^{35}$ and the demand for drugs used to treat patients with COVID-19 including but not limited to tocilizumab, could surpass the ability to manufacture these agents. Additionally, in some cases, access to tocilizumab and sarilumab is limited despite adequate supply. For example, the study protocol for sarilumab in COVID19-related ARDS initially excluded individuals who have recently been treated with any other investigational drugs, high-dose steroids or cyclophosphamide chemotherapyeffectively preventing numerous patients with cancer and patients receiving immunotherapy from receiving this potentially lifesaving intervention-however, amended exclusion criteria may relax these requirements. Ongoing and future clinical trials should consider the unique characteristics of oncology patients in their design (including inclusion and exclusion criteria), in light of the fact that the large, immune-suppressed population of patients with cancer may be particularly susceptible to severe complications of COVID-19. ${ }^{36}$ In addition, although data are not available, it is unknown whether pulmonary manifestations of COVID-19 may be potentiated or attenuated in oncology patients being treated with immunotherapeutic approaches that themselves can have significant pulmonary toxicity, including checkpoint inhibitors and CAR T cells.

Although tocilizumab and sarilumab are presently the most well-studied anti-IL-6 agents in the COVID-19 setting, numerous agents have been developed to modulate pro-inflammatory signaling at multiple levels in the pathway. An immunology-informed approach could identify potential alternatives to tocilizumab and sarilumab, broadening the population of patients that may receive treatment to ameliorate the complications of COVID19 , and thus 'flattening the curve' for total patient days requiring ICU support, including mechanical ventilation.

\section{OVERVIEW OF IL-6 SIGNALING AND REGULATION}

IL-6 is a pleiotropic cytokine with nearly ubiquitous expression in stromal and immune cells. In the airway, alveolar macrophages produce IL-6, and expression may be 
induced in epithelial cells by IFN $\gamma$ and danger-associated molecular patterns (DAMPs). ${ }^{37} 38$ The effects of IL-6 are context-specific and may be both pro-inflammatory and anti-inflammatory. Although IL-6 is essential for both innate and adaptive immunity-patients with autoantibodies to the cytokine or germline mutations in its downstream signaling effectors are susceptible to recurrent infections and often die prematurely due to pneumonia. In turn, uncontrolled IL-6 expression leads to profound inflammatory damage to host cells. ${ }^{11}{ }^{39}$ Under homeostatic conditions, serum concentrations of IL-6 are typically lower than picograms per $\mathrm{mL}$, but under conditions of severe inflammation, levels may reach up to nanograms per $\mathrm{mL}$, as seen in severe $\mathrm{CRS}^{31}$ or even micrograms per $\mathrm{mL}$ in fatal sepsis. ${ }^{40}$

\section{Regulation of IL-6 expression}

Expression of IL-6 is regulated at multiple levels including chromatin accessibility, transcription, mRNA export, post-transcription and translation. TNF $\alpha$ and IL-1 $\beta$ also induce IL-6 expression. ${ }^{41}$ Coronavirus' spike proteins have also been shown to directly promote IL-6 production in immune and epithelial cells. Cultured SARS-CoVinfected bronchial epithelial cells secrete IL- $6,{ }^{42}$ and murine macrophages upregulate IL-6 and TNF $\alpha$ through a nuclear factor-kB-dependent pathway in response to viral $\mathrm{S}$ protein. ${ }^{43}$

\section{IL-6 signaling (classical and trans)}

Signaling through the IL-6 receptor requires assembly at the cell membrane of a complex consisting of IL-6 bound to both the $80 \mathrm{kDa}$ type 1 cytokine a-receptor subunit (IL6R, also called CD126) and a $130 \mathrm{kDa}$ signal-transducing b-receptor glycoprotein (gp130; also called CD130). This trimeric complex homodimerizes, leading to receptor activation. ${ }^{11}{ }^{44}$ Expression of the membrane-bound form of IL-6R is largely restricted to hepatocytes, megakaryocytes and leukocytes, ${ }^{45}$ yet two independent pathways generate a soluble form of the receptor: cleavage by membrane metalloproteinases, primarily ADAM10 and ADAM17, as well as alternative splicing. ${ }^{45-47}$ Soluble IL-6/IL-6R receptor complex can also bind gp130, activating the downstream signaling cascade. The ubiquitous expression of gp130, which has been detected in all human tissues examined, underlies the pleiotropic effects of IL-6, and the near universal responsiveness to the cytokine across cell types. Receptor activation through the membrane-bound IL-6R versus the soluble form of IL-6R are referred to as classical and trans signaling, respectively. Generally, classical signaling contributes to regenerative and anti-inflammatory responses, whereas trans signaling is pro-inflammatory and plays a role in causing tissue damage.

\section{Signal transduction}

Ligand binding at the IL-6R activates multiple intracellular signaling cascades, including Janus kinase (JAK) / signal transducer and activation of transcription (STAT) pathways and the phosphatidylinositol 3-kinase (PI3K) pathway. Of potential importance in the context of COVID-19, the activation of JAK1 and STAT3 kinases by IL-6R initiates a pro-inflammatory transcriptional program associated with proliferation, differentiation, recruitment, survival and transformation in $\mathrm{T}$ and $\mathrm{B}$ cells and myeloid cells. ${ }^{11445}$ An overview of IL-6 signal transduction with modes of action of approved IL-6modulatory therapies is illustrated in figure 1.

\section{POTENTIAL THERAPEUTIC STRATEGIES}

IL-6 blocking agents have been developed in the recent years to treat rheumatological conditions. Tocilizumab was approved by the FDA in 2010 to treat moderately to severely active rheumatoid arthritis. While other indications followed, it was not until August 2017 that it received approval for the treatment of CAR T cell-induced CRS.

Many other agents have since been developed or are under investigation to modulate the circulating levels, receptor binding and/or biological effects of IL-6. The FDA-approved agents are listed in table 1, whereas therapies that are not yet approved, but are in later-stage clinical development are described in online supplementary table 1. Caution should be exercised in attempting to equate antireceptor and antiligand antibodies. The safety and efficacy of some of these agents that have not yet achieved regulatory approval has not been established. Furthermore, none of the agents has achieved regulatory approval for use in patients with COVID-19, although China has issued treatment guidelines recommending tocilizumab for severe SARS-CoV-2 pneumonia.

As with all immune-modulatory agents, patients treated with anti-IL-6/IL-6R agents are at increased risk for infections, most commonly by opportunistic bacterial and fungal pathogens. Patients with latent tuberculosis are at risk of reactivation with IL- 6 blockade. Other common side effects that may be concern in the COVID-19 setting include hypotension, decreased platelet counts, liver toxicity, risk of gastrointestinal (GI) perforation and difficulty breathing.

\section{Interleukin-6 antagonists}

- Tocilizumab (Actemra ${ }^{\circledR}$, Genentech) is an IL-6R antagonist antibody also known as atlizumab. It is indicated for the treatment of rheumatoid arthritis, giant cell arteritis, polyarticular juvenile idiopathic arthritis, systemic juvenile idiopathic arthritis and CAR-T cellinduced severe CRS.

- Sarilumab (Kevzara ${ }^{\circledR}$, Regeneron/Sanofi) is an IL-6R antagonist antibody indicated for the treatment of adult patients with moderately to severely active rheumatoid arthritis who have had an inadequate response or intolerance to one or more disease-modifying antirheumatic drugs.

- Siltuximab (Sylvant ${ }^{\mathrm{TM}}$, EUSA Pharma) is an anti-IL-6 antibody, distinct from tocilizumab and sarilumab, as it targets the soluble cytokine and not the receptor. It 


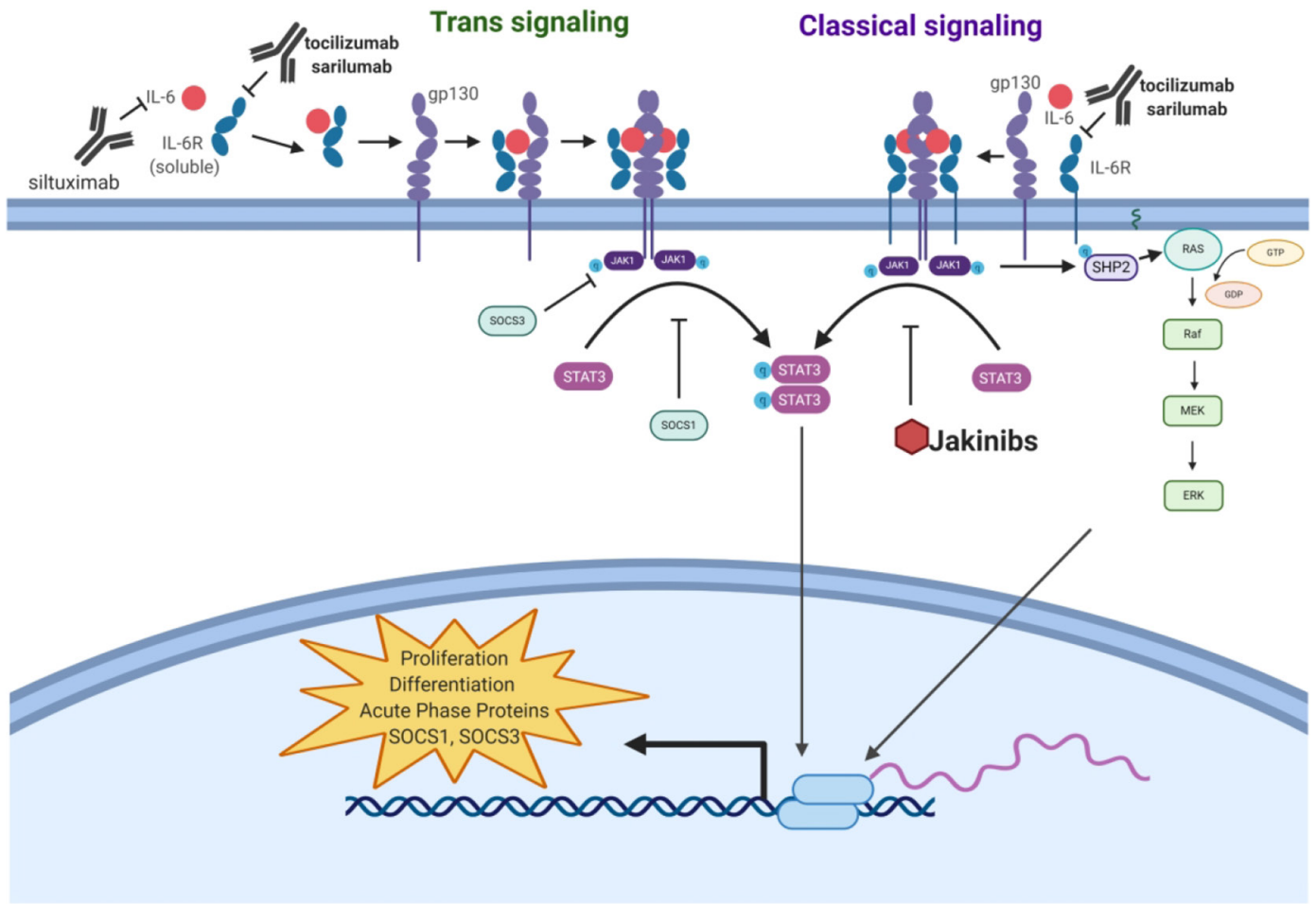

Figure 1 Interleukin 6 (IL-6) signaling cascade. Antibodies such as tocilizumab, sarilumab and siltuximab inhibit IL-6 signaling by antagonizing ligand-receptor engagement, whereas Jakinibs prevent the downstream signaling cascade. The intracellular domain of gp130 is constitutively associated with the Janus family tyrosine kinases JAK1 and JAK2. On homodimerization, JAKs autophosphorylate and JAK1 phosphorylates 5 tyrosine residues in the cytoplasmic tail of gp130, leading to the activation of multiple intracellular signaling cascades. Recruitment and phosphorylation of STAT3 initiates its homodimerization and nuclear trafficking, initiating a transcriptional program associated with proliferation, differentiation, recruitment, survival and transformation in T and B cells and myeloid cells. A negative feedback loop modulates activation of the IL-6-JAK/STAT cascade, as STAT3 upregulates SOCS1 and SOCS3, which directly inhibits the catalytic activity of JAK by binding to phosphorylated gp130 at tyrosine 759 , and stops JAK activation through direct binding. ${ }^{11}$ Phosphorylated gp130 is also a binding site for SH2 domain tyrosine phosphatase 2 (SHP2), activating a cascade involving RAS, RAF and mitogen-activated protein kinases (MAPK), which culminates in the activation of various transcription factors involved in increasing cell growth, antibody synthesis and acute phase protein generation. JAK also phosphorylates phosphatidylinositol-4,5-bisphosphate (PIP2), which is then phosphorylated by phosphoinositide 3-kinase (PI3K) to become phosphatidylinositol-3,4,5-trisphosphate (PIP3), which then phosphorylates $\mathrm{PkB} / \mathrm{Akt}$ serine/threonine kinase to modulate expression of several genes involved in cellular survival. ${ }^{12}$

is indicated for the treatment of patients with Castleman's disease. Of note, it was not studied in patients with HIV or human herpesvirus-8 (HHV-8) infections as preclinical studies showed lack of binding to virally produced IL- 6 . Therefore, it is only indicated in those patients who are HIV and HHV-8 negative.

\section{Janus kinase/signal transducer and activation of transcription (JAK/STAT) inhibitors}

While encouraging preliminary results have been observed with IL-6 blockade, potential constraints on the supply of IL-6/IL-6R-targeting antibodies may limit access to these drugs and the numbers of patients that can benefit. In order to expand the spectrum of patients who may access IL-6-modulatory therapies, alternative targets within the cytokine's inflammatory signaling cascade could be considered.

IL-6 signaling takes place via two mechanisms: binding to a higher affinity membrane-bound receptor (classical) or soluble IL-6 receptor (trans). ${ }^{414}$ Both lead to activation of JAK/STAT signaling downstream through JAK1 and STAT3, on tyrosine phosphorylation on the gp130 receptor's cytoplasmic tail. JAK/STAT signaling is also activated by other pro-inflammatory cytokines that are observed to be elevated in COVID-19, particularly IFN $\gamma$ (although IFN signaling is primarily via STAT1). STATs also play important roles in non-canonical cell signaling pathways, including activity of non-tyrosine phosphorylated STATs, mediation of DNA methylation, regulation of cell adhesion and mitochondrial activity. ${ }^{48}$

Small molecules targeting this pathway have been successfully introduced into the clinic, and are a therapeutic option in a number of inflammatory processes, ${ }^{49}$ including graft versus host disease and HLH. ${ }^{50}$ In xenograft models, ruxolitinib was able to prevent CRS after CAR Tcell therapy. ${ }^{52}$ Importantly, a phase III trial is being initiated to assess ruxolitinib in combination with standard of care compared with standard of care alone in patients with severe COVID-19 pneumonia as a result of SARS-CoV-2 infection. ${ }^{53}$ Additionally, a phase II single-arm study of fedratinib is planned. 
Table 1 Food and Drug Administration-approved agents: IL-6

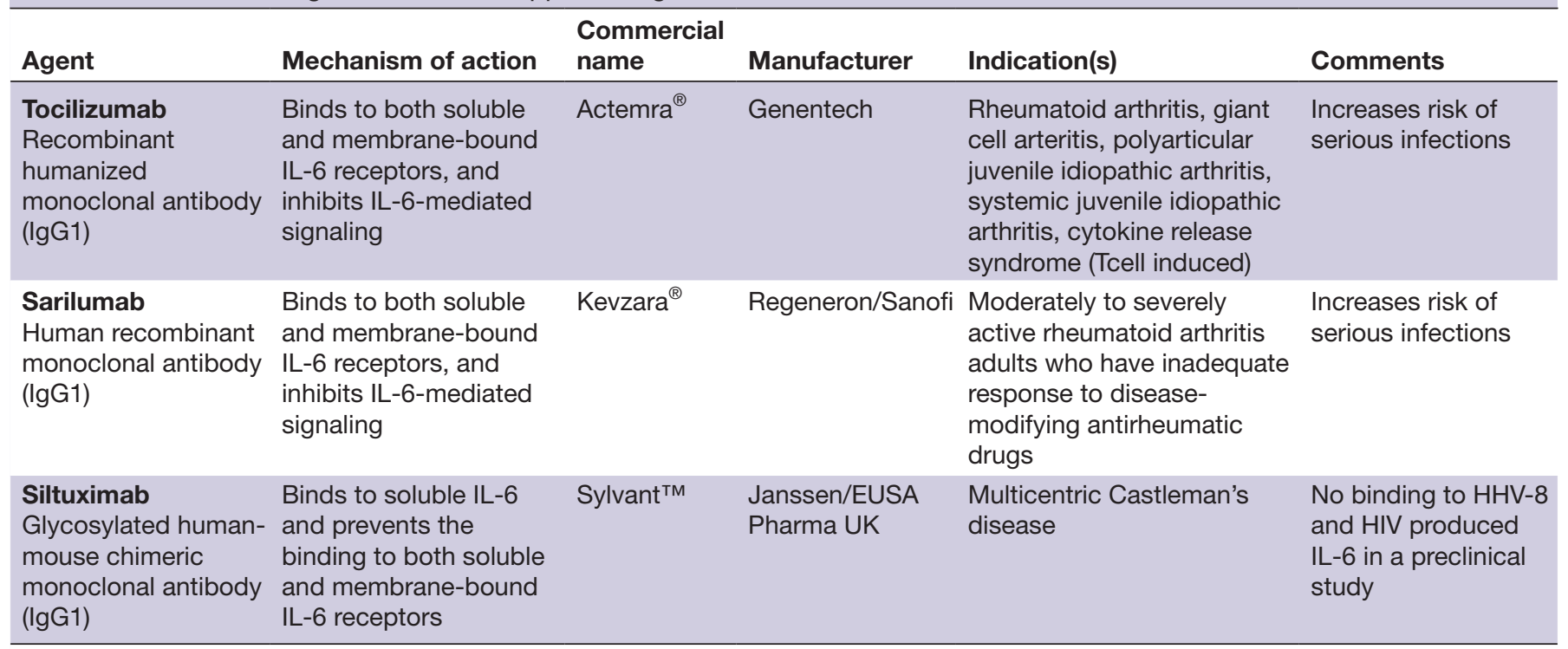

HHV-8, human herpesvirus-8; IL, interleukin.

The rationale for developing these agents as an option to prevent or treat cytokine release in COVID-19 is compelling, especially given the relative ease of manufacturing small molecules at scale as compared with biologics. The safety profiles of JAK inhibitors are generally manageable and predictable including increased risk of viral infections, lower GI complications and anemia and leukopenia. ${ }^{54}{ }^{55}$ Because IL-6 signaling primarily occurs through JAK1, the selectivity of JAK inhibitors should be considered before their use for COVID-19. Additionally, 'Jakinibs' are oral tyrosine kinase inhibitors, ${ }^{54}$ which may not be easily administered/absorbed in patients with very severe ongoing systemic inflammatory response.

- Ruxolitinib (Jakavi/Jakafi ${ }^{\circledR}$, Incyte) is an oral JAK inhibitor with selectivity for JAK1 and JAK2 indicated for treatment of intermedia-risk or high-risk myelofibrosis, polycythemia vera unresponsive or intolerant to hydroxyurea and steroid-refractory graft versus host disease in adult and pediatric patients aged 12 years and older.

- Tofacitinib (Xeljanz ${ }^{\circledR}$, Jakvinus, Pfizer) is an oral JAK inhibitor with selectivity for JAK1 and JAK3 indicated for the treatment of rheumatoid arthritis, psoriatic arthritis and ulcerative colitis. The occurrence of serious infections and lymphoid-associated malignancies have led to a current black box warning imposed by the FDA.

- Baricitinib (Olumiant ${ }^{\circledR}$, Eli-Lilly) is an oral JAK inhibitor with specificity for JAK1 and JAK2 indicated for the treatment of adult patients with moderately to severely active rheumatoid arthritis who have had an inadequate response to one or more TNF antagonist therapies. The occurrence of serious infections, lymphoma and thrombosis have led to a current black box warning imposed by the FDA.
- Peficitinib (Smyraf ${ }^{\circledast}$, Astellas) is an oral pan-JAK inhibitor with JAK1, JAK2, JAK3 and tyrosine kinase 2 activity approved only in Japan and indicated for the treatment of rheumatoid arthritis in patients who have inadequate response to conventional therapies.

- Upadacitinib (Rinvoq TM, AbbVie) is a second-generation oral JAK inhibitor with high specificity for JAK1 that is indicated for the treatment of adults with moderately to severely active rheumatoid arthritis who have had an inadequate response or intolerance to methotrexate. The occurrence of serious infections, lymphoma and thrombosis has led to a current black box warning imposed by the FDA.

- Fedratanib (Inrebic ${ }^{\circledR}$, Impact Biomedicines/Celgene) is an oral semi-selective JAK2 JAK inhibitor indicated for the treatment of adult patients with intermediate or high-risk primary or secondary (postpolycythemia vera or postessential thrombocythemia) myelofibrosis. The occurrence of serious and fatal encephalopathy, including Wernicke's, has led to a black box warning imposed by the FDA.

\section{Interleukin-1 inhibitors}

Modulation of IL-1 signaling, especially through the IL-1 $\beta$ isoform, could also potentially attenuate the exuberant inflammatory response that accompanies lung pathology in COVID-19 upstream of IL-6. Although serum IL-1 has not necessarily correlated with severity of SARS-CoV-2 disease in published reports, its function as a master cytokine elicits large effects with small perturbations. ${ }^{56-58}$ IL-1 signaling orchestrates the acute phase of response to infections and has also been demonstrated to influence the differentiation of lymphocytes, particularly Th 17 cells. Of the two isoforms, IL-1 $\beta$ is predominantly associated with pulmonary pathology in ARDS. ${ }^{50}$ Although data 
on the immunopathology underlying ARDS in COVID-19 are lacking, a pro-inflammatory Th17 signature has been observed in patients infected with SARS-CoV- $2^{61}$ as well as in patients with MERS-CoV. ${ }^{62}$ Additionally, IL-1 has been shown to be a key cytokine driving pro-inflammatory activity in bronchoalveolar lavage fluid of patients with acute lung injury. ${ }^{60}$

The IL-1 family of cytokines are major regulators of the acute phase response, functioning to control inflammatory reactions in response to PAMPs and DAMPs released from damaged or infected cells. ${ }^{5763}$ Hundreds of genes are transcriptionally upregulated by IL-1 signaling, including IL-6. IL-1-modulating therapies have been FDA approved for a number of indications, primarily for auto-inflammatory diseases where the primary drivers of pathology are innate immune cells rather than the $\mathrm{T}$ cell and Bcell compartments. ${ }^{64}$ Three IL-1-modulating therapies have been approved by the FDA, and each agent inhibits signaling through a distinct mechanism, which may have important implications for their possible use in treating COVID-19.

Multiple mechanisms modulate IL-1 signaling, including the soluble IL-1 receptor antagonist (IL-1RA), which is secreted by immune cells, epithelial cells and adipocytes ${ }^{65}$ and the decoy receptor IL-1RII, which exists in both membrane-bound and soluble forms and scavenges IL-1 $\beta$ with high affinity. ${ }^{66}$ These endogenous factors have formed the basis for several IL-1-targeting therapeutics, including anakinra (a receptor antagonist) and rilonacept (a receptor trap). Additionally, an antiIL-1 $\beta$ antibody, canakinumab, has been FDA approved for a variety of auto-inflammatory diseases.

Anakinra is a recombinant form of IL-1RA that lacks glycosylation and is modified with the addition of a single methionine residue at the N-terminus. Although several randomized trials failed to demonstrate statistically significant 28-day survival benefits for IL-1R antagonist therapy for sepsis, ${ }^{67-69}$ a reanalysis showed profoundly improved outcomes among the subset of patients with disseminated intravascular coagulation and hepatobiliary dysfunction, hallmarks of secondary MAS. ${ }^{70}$ Anakinra has also proven effective and gained FDA approval for the treatment of a variety of autoinflammatory disorders including CAPS as well as rheumatoid arthritis. ${ }^{563}$ Anakinra is short-acting, with a plasma half-life of roughly $4-6$ hours. ${ }^{71}$

Anecdotal evidence has emerged that anakinra effectively modulates late-onset, tocilizumab-refractory CRS with clinical features similar to HLH/MAS secondary to CAR T cell therapy. ${ }^{72}$ Initial experience from the Northern Italian SARS-CoV-2 outbreak, however, has indicated that anakinra monotherapy did not provide clinical benefit when administered to patients with severe ARDS. ${ }^{33}$ It is possible that multiple mechanisms need to be targeted, as cytokine profiles from patients with COVID-19 demonstrate marked elevation of multiple factors beyond IL-1, including IL-6, IL-17, TNF $\alpha$ and IFN $\gamma$. An ongoing clinical trial is evaluating anakinra in combination with the IFN $\gamma$ inhibitor emapalumab for severe ARDS in COVID-19 (NCT04324021).

The overall safety profile of anti-IL-1 therapies is acceptable. As with any cytokine modulator, IL-1 blockade carries increased risk of bacterial infections, but after many years of clinical experience and tens of thousands of patients treated, it has become apparent that opportunistic infections are highly rare with anakinra treatment, even among people at high risk for tuberculosis reactivation. Of note, anti-IL-1 therapy is associated with a reduction in circulating neutrophil counts, ${ }^{58}$ which may be clinically significant given that a high NLR (Neutrophil to Leukocyte Ratio) is predictive of poor prognosis in COVID-19. Evidence for improved outcomes after using IL-1 modulating therapies for CRS is lacking and variable. The timing of IL-R1 antagonist administration may be critical, and limited benefit may be obtained with treatment of already-established ARDS. Targeting IL-1 $\beta$ directly, either by reducing its effective concentration via a receptor trap or monoclonal antibody may also be impactful.

- Anakinra (Kinaret ${ }^{\circledR}$, Sobi) is a modified, recombinant human IL-1R antagonist indicated for the treatment of adult rheumatoid arthritis and neonatal-onset multisymptom inflammatory disease.

- Rilonacept (Arcalyst ${ }^{\circledR}$, Regeneron) is a dimeric fusion protein consisting of the extracellular domains of IL-1R and IL-1RAcP, linked by the Fc portion of human anti-IL-1 IgG1 indicated for the treatment of adults and children 12 years of age and older with CAPS.

- Canakinumab (Ilaris ${ }^{\circledR}$, Novartis) is a human monoclonal anti-IL-1 $\beta$ antibody indicated for the treatment of periodic fever syndromes (including CAPS) and systematic juvenile idiopathic arthritis.

\section{Tumor necrosis factor alpha inhibitors}

Ligands and receptors of the tumor necrosis factor superfamily play central roles in regulation of the immune system and tissue homeostasis. Although TNF signaling is vital for antipathogen immune responses and is protective in a variety of viral infections including smallpox, ${ }^{73}$ West Nile virus ${ }^{74}$ and influenza, ${ }^{75}$ elevated levels of TNF $\alpha$ have been linked to pulmonary pathology in acute lung injury. Elevated TNF $\alpha$ is observed in both plasma and bronchoalveolar lavage fluid in patients with ARDS, and expression of the cytokine directly leads to increased endothelial permeability along with impaired alveolar fluid clearance due to downregulation of epithelial sodium channels. ${ }^{7677}$ Elevated serum $\mathrm{TNF} \alpha$ has been reported to correlate with severe disease in COVID- $19,{ }^{8}$ and the SARS-CoV S protein has been demonstrated to induce TNF $\alpha$ and IL-6 upregulation in murine macrophages. ${ }^{43}$

The primary sources of TNF $\alpha$ are stimulated monocytes, fibroblasts and endothelial cells, although macrophages, T cells, B lymphocytes, granulocytes, smooth muscle cells, eosinophils, chondrocytes, osteoblasts and mast cells all produce TNF $\alpha$ as well. ${ }^{77-79} \mathrm{TNF} \alpha$ is synthesized as a membrane-protein and cleaved by ADAM17 to 
release its soluble form. Both the soluble and membranebound forms of TNF $\alpha$ are active, although their affinities to TNF-family receptors varies. TNF $\alpha$ signaling is complex, and may involve as many as 29 different tumor necrosis factor receptor (TNFR) family members. In particular, TNFR1 is widely expressed; as is the case for IL-6 this broad-based expression gives rise to pleiotropic systemic effects.

Multiple TNF $\alpha$ inhibitors have been developed for the treatment of inflammatory diseases, and some have demonstrated benefit in animal models of acute lung injury and respiratory distress. ${ }^{80}$ These results have not borne out in humans, however, as anti-TNF $\alpha$ therapy failed to protect patients from sepsis-induced acute lung injury $^{81} 82$ and did not improve outcomes for chronic obstructive pulmonary disease. ${ }^{83}$ Preliminary reports from China indicate that anti-TNF $\alpha$ antibody offers limited benefit for patients with SARS-CoV-2 infections with established ARDS, ${ }^{84}$ although modulating the pathway through other targets or at different timepoints may be more efficacious. In the oncology setting, the anti-TNF $\alpha$ antibody infliximab is commonly used for the management of immune-related adverse events secondary to immune checkpoint inhibitor therapy. Additionally, success has been reported with the use of the TNF $\alpha$ receptor trap etanercept for the treatment of CRS secondary to CAR T cell therapy ${ }^{85}$ and in MAS, ${ }^{86}$ but no prospective, large-scale trials have demonstrated efficacy for TNF modulation in the setting of viral cytokine storm. Adverse effects of concern for anti-TNF $\alpha$ therapy include dampened cell-mediated immune responses. All of the approved agents carry black box warning labels for increased risk of serious, life-threatening opportunistic bacterial and fungal infections and patients with latent tuberculosis should not receive these therapies.

- Infliximab (Remicade ${ }^{\circledR}$, Janssen) is a chimeric monoclonal anti-TNF $\alpha$ antibody indicated for the treatment of inflammatory bowel diseases in adults and children, rheumatoid arthritis, ankylosing spondylitis, psoriatic arthritis and plaque psoriasis.

- Etanercept (Enbre ${ }^{\mathbb{B}}$, Amgen) is a receptor trap consisting of TNF-R2 fused to IgG1 Fc indicated for the treatment of rheumatoid arthritis, ankylosing spondylitis, psoriatic arthritis and plaque psoriasis.

- Adalimumab (Humira ${ }^{\circledR}$, AbbVie) is a human monoclonal anti-TNF $\alpha$ antibody indicated for the treatment of rheumatoid arthritis, ankylosing spondylitis, Crohn's disease, psoriatic arthritis and plaque psoriasis.

- Certulizumab pegol (Cimzia $\left.{ }^{\circledR}, U C B\right)$ is a human monoclonal anti-TNF $\alpha$ antibody conjugated to a $40 \mathrm{kDa}$ polyethylene glycol indicated for reducing signs and symptoms in Crohn's disease and the treatment of rheumatoid arthritis, ankylosing spondylitis and psoriatic arthritis.

- Golimumab (Simponi ${ }^{\circledR}$, Janssen) is a human monoclonal anti-TNF $\alpha$ antibody indicated for the treatment of rheumatoid arthritis, ankylosing spondylitis, psoriatic arthritis and Crohn's disease.

\section{Interferon gamma}

IFN $\gamma$ is a pleiotropic cytokine that plays an essential role in multiple phases of immune and inflammatory responses. The IFN family of proteins encompasses three distinct classes, with variable direct antiviral and immunemodulatory activities. ${ }^{87}$ The IFN $\gamma$ receptor is expressed on both malignant and non-malignant cell populations. ${ }^{88}$

On receptor binding, IFN $\gamma$ initiates a signaling cascade through JAK1 and JAK2 activation, which leads to STAT1 homodimerization and nuclear translocation and transcriptional activation of a wide array of IFN-inducible genes through the GAS enhancer element. ${ }^{88}{ }^{89}$ IFN $\gamma$ has been implicated as an important downstream effector cytokine in the antitumor immune response, and in the immune response to various infectious pathogens, including viruses. ${ }^{90}$ Although protective in the context of antiviral host defense, IFN $\gamma$ also has been implicated in the pathogenesis of 'cytokine storm' and in various autoimmune diseases. ${ }^{91}{ }^{92}$ Anti-IFN therapy has been investigated in HLH, rheumatoid arthritis, multiple sclerosis, Crohn's disease and psoriasis. ${ }^{91} 93$

Elevated serum IFN $\gamma$ has been associated with severe acute respiratory distress in COVID-19. ${ }^{81} 3694$ Additionally, IFN $\gamma$ enhances IL-6 production in monocytes ${ }^{95}$ and an IFN $\gamma$-related cytokine storm syndrome was reported in some patients during the 2003 SARS coronavirus outbreak. ${ }^{96}$ Anti-IFN antibodies have been demonstrated to alleviate acute lung injury induced by severe H1N1 influenza infection in murine models, ${ }^{97}$ and a trial of the human monoclonal anti-IFN $\gamma$ emapalumab in combination with the IL-1 receptor antagonist anakinra for COVID-19 is ongoing. ${ }^{98}$

Anti-interferon therapy is approved in the US for the treatment of primary HLH. In the pivotal trial for the approval of emapalumab for HLH, the most commonly reported adverse events included infections, hypertension, infusion reactions and fever. ${ }^{99}$

- Emapalumab (Gamifant ${ }^{\circledR}$, Sobi) a human monoclonal antibody that binds to soluble and receptor-bound forms of IFN $\gamma$ and is approved for the treatment of primary HLH in patients with refractory, recurrent or progressive disease or intolerance to conventional therapy

\section{Granulocyte macrophage-colony stimulating factor}

Alveolar macrophages can play a central role in the inflammatory pathology of ARDS through the release of a wide array of bioactive factors that damage or induce cell death in the lung epithelium such as proteases, reactive oxygen species, eicosanoids, phospholipids and cytokines including IL-1, IL-6 and TNF $\alpha .{ }^{77100}$ One key cytokine that regulates macrophage number and function is granulocyte macrophage-colony stimulating factor (GM-CSF), a monomeric glycoprotein secreted by macrophages, $\mathrm{T}$ cells, mast cells, natural killer cells, endothelial cells and fibroblasts. GM-CSF is upstream of IL-6 and induces an inflammatory transcriptional program through JAK/ STAT signaling. ${ }^{101}$ Inactivation of GM-CSF in CAR T 
cells dramatically lowers IL-6 and IL-8 secretion ${ }^{102}$ and therapeutic inhibition of GM-CSF reduces CAR T-cellassociated CRS in mouse models. ${ }^{103}$

Initial evidence from a study of 52 patients with COVID-19 reported from Wuhan, China, elevated levels of circulating GM-CSF were associated with worse clinical outcomes. ${ }^{182}$ Additionally, analysis of peripheral blood samples from 33 patients with COVID-19 with pneumonia found increased numbers of pathogenic Th1 cells (GM$\left.\mathrm{CSF}^{+} \mathrm{IFN}^{+}\right)$and inflammatory monocytes $\left(\mathrm{CD} 14^{+} \mathrm{CD}^{+} 6^{+}\right.$ with high expression of IL-6) in patients admitted to the ICU as compared with non-critical patients. ${ }^{104}$ In early April 2020, several studies evaluating anti-GM-CSF antibodies for COVID-19 treatment were initiated in rapid succession, including trials of lenzilumab, ${ }^{105}$ TJM-2, ${ }^{106}$ gimsilumab $^{107}$ and namilumab. One anti-GM-CSF antibody, lenzilumab, received emergency investigational new drug approval for compassionate use in patients with COVID-19. Although the safety profiles of anti-GM-CSF antibodies have been acceptable in phase I and phase II trials, it is important to note the potential for lung toxicities and pneumonia with these agents. ${ }^{101}$

- Lenzilumab (Humanigen) is a human monoclonal anti-GM-CSF antibody approved for compassionate use in patients with COVID-19. A phase III trial for COVID-19 is ongoing. Lenzilumab was originally developed for the treatment of chronic myelomonocytic leukemia and has also been evaluated for inadequately controlled asthma and rheumatoid arthritis.

- Namilumab (Izana Bioscience) is a human monoclonal anti-GM-CSF antibody that has been evaluated in phase II trials for plaque psoriasis and rheumatoid arthritis. It is being evaluated in a two center compassionate use study for COVID-19 by UK-based Izana Bioscience. In the rheumatoid arthritis study, a few patients experienced AEs indicative of pulmonary alveolar proteinosis, but following review all suggestive cases were given an alternative diagnosis.

- Gimsilumab (Roivant) is a human monoclonal antiGM-CSF antibody developed for rheumatoid arthritis. It has demonstrated favorable safety and tolerability with no serious adverse events reported in two phase I trials in healthy adult volunteers. Trials in patients with COVID-19 will be prioritized instead of a planned phase II study in patients with rheumatoid arthritis.

- TJM-2 (I-Mab Biopharma) is a neutralizing antibody against GM-CSF that is being developed to treat cytokine storm in critically ill patients with COVID-19. It previously exhibited favorable safety, tolerability, pharmacokinetic/pharmacodynamic and immunogenicity profiles in a phase I dose-escalation study in the USA and received IND (Investigational New Drug) clearance from China's National Medical Products Administration for a multiple-dose phase Ib study in patients with rheumatoid arthritis.

- Otilimab (GSK) is a human GM-CSF inhibitory antibody that started phase III evaluation for rheumatoid arthritis in July 2019. During the phase II trials of otilimab, no serious adverse events and pulmonary toxicity, including pulmonary alveolar proteinosis, were observed.

\section{Interleukin-17 and interleukin-23 inhibitors}

IL-17 is a pro-inflammatory cytokine. It is produced by Th17 cells on stimulation with IL-23. The IL-17/ IL-23 axis stimulates the secretion of cytokines know to mediate inflammation, including IL-6, and IL-6 (in the presence of TGF- $\beta$ ) skews naive CD4 T cells toward the Th17 phenotype. ${ }^{108}$ IL-17/IL-23 signaling has been postulated to mediate cross-talk between the innate and the adaptive immune system. ${ }^{109} \mathrm{~A}$ characteristic Th17 signature has been noted in patients with COVID-19 ARDS, ${ }^{10}$ and modulation of IL-17 signaling through the JAK/STAT inhibitor fedratinib has been proposed, although this indication is currently speculative. ${ }^{61}$ Clinically, the use of agents that modulate this axis have been mostly used in the treatment of chronic conditions such as psoriasis ${ }^{109}$ and the most frequently observed adverse events have been nasopharyngitis, upper respiratory tract inflammation and injection site reactions. ${ }^{110}$ Although these agents have the potential to dampen IL-6 production and signaling, the use of IL-17/IL-23 modulators in conditions such as CRS has not yet been widely tested.

- Secukinumab (Cosentyx ${ }^{\circledR}$, Novartis) is a human IL-17A antagonist indicated for the treatment of moderateto-severe plaque psoriasis, psoriatic arthritis and ankylosing spondylitis.

- Ixekizumab (Taltz ${ }^{\circledR}$, Eli-Lilly) is a humanized IL-17A antagonist indicated for the treatment of adults with moderate-to-severe plaque psoriasis.

- Brodalumab (Siliq ${ }^{\circledR}$, Valeant/LEO Pharma) is a human IL-17 receptor A antagonist indicated for the treatment of moderate-to-severe plaque psoriasis. The occurrence of suicidal ideation has led to a black box warning imposed by the FDA.

- Ustekinumab (Stelara ${ }^{\circledR}$, Janssen) is a human IL-12 and IL-23 antagonist indicated for the treatment of adult patients with moderate-to-severe plaque psoriasis, active psoriatic arthritis and moderately to severely active Crohn's disease.

- Guselkumab (Tremfya ${ }^{\circledR}$, Janssen) is an IL-23 blocker indicated for the treatment of adult patients with moderate-to-severe plaque psoriasis.

- Tidrakizumab-asmn (Ilumya ${ }^{\mathrm{TM}}$, Sun Pharma Global) is an IL-23 antagonist indicated for adults with moderateto-severe plaque psoriasis.

- Risankizumab-rzaa (Skyrizi ${ }^{\mathrm{TM}}$, AbbVie) is an IL-23 antagonist indicated for the treatment of plaque psoriasis

\section{CONCLUSION}

The COVID-19 pandemic caused by SARS-CoV-2 highlights an urgent need for all healthcare stakeholders including government organizations, academic centers, community centers, philanthropic organizations, advocates, pharmaceutical and biotechnology industries to 
develop a coordinated and flexible approach to increase the availability of resources.

Modulation/inhibition of the severe inflammatory state in patients with COVID-19, characterized by elaboration of various inflammatory mediators, including IL-6, is a potentially important strategy to treat and/or limit severe COVID-19 pulmonary complications, including ARDS. If successful across the broader population of patients with COVID-19, strategies such as anti-IL-6-directed therapy could reduce the needs for ICU support and mechanical ventilation, and ultimately decrease mortality.

Randomized phase III trials are currently evaluating the efficacy of anti-IL-6-directed agents, including tocilizumab and sarilumab, as well as the JAK/STAT inhibitor ruxolitinib, and will provide definitive data regarding the use of these agents in patients with COVID-19. As described here, other anti-IL-6 agents, including small molecule inhibitors of IL-6 signaling, and other anticytokine inhibitors may warrant investigation, particularly in the setting of overwhelming demand for agents to modulate the inflammatory state in patients with COVID-19. Ongoing studies are also investigating other strategies, such as the use of eculizumab (a monoclonal antibody that targets complement protein C5, approved for paroxysmal nocturnal hemoglobinuria), or some TLR7-8 inhibitors such as M5049. In all likelihood, a combinatorial approach encompassing antivirals such as remdesivir and potentially cytokine-modulatory therapies may be needed to successfully treat the infection with SARS-CoV-2 and the full spectrum of associated complications.

The US FDA has announced a new program, CTAP (Coronavirus Treatment Acceleration Program), to expedite drug development for COVID-19. While this is encouraging news and the appropriate way to proceed from a drug development perspective, the healthcare community and, more importantly, the affected patients, need effective treatments without delay, especially as the numbers of cases in the USA and several countries around the world continue to grow exponentially. Consideration also should be given to focus efforts on rapidly expanding the ability of clinicians and clinical investigators to access investigational anti-IL-6 agents, in particular for those agents where phase II and/or phase II studies have been completed, and acceptable safety has been demonstrated. Use of cytokine-modulatory agents during these extreme circumstances may additionally warrant consideration, and definitive prospective randomized trials also should be conducted with all due haste.

\section{Author affiliations}

${ }^{1}$ MacroGenics Inc, Rockville, Maryland, USA

2John Wayne Cancer Institute and Cancer Clinic, Providence Saint John's Health Center, Santa Monica, California, United States

${ }^{3}$ Providence Los Angeles Metro Hospitals, Santa Monica, California, United States ${ }^{4}$ Herbert Irving Cancer Center, Columbia University Medical Center, New York, New York, USA

${ }^{5}$ Earle A Chiles Research Institute, Portland, Oregon, USA

${ }^{6}$ University of Science and Technology of China, Hefei, Anhui, China

${ }^{7}$ A.O.R.N. dei Colli Monaldi-Cotugno-CTO Hospitals, Naples, Italy
${ }^{8}$ Perlmutter Cancer Center, NYU Langone Health, New York, New York, USA

${ }^{9}$ Frederick, Maryland, USA

${ }^{10}$ Istituto Nazionale Tumori IRCCS Fondazione 'G. Pascale', Napels, Italy

Twitter Fernanda I Arnaldez @Farnaldez3 and Vincenzo Montesarchio @Vincenzo Montesarchio

Acknowledgements The authors would like to thank the SITC staff for their contributions including Sam Million-Weaver, PhD for medical writing and editorial support and Angela Kilbert for project management and assistance. The authors would also like to thank the society for supporting the manuscript development.

Contributors JMW and BAF conceptualized the paper, served as authors on the paper, provided guidance in the development and reviewed and provided substantial comment on the content. FIA and SMW wrote the paper based on a review of the published literature and guidance from the other authors. FIA sourced the content of the supplemental table and SMW made the figure. PAA, CGD, BF, SJO'D, WJU and JSW provided substantial contributions to the content as well as reviewed and edited drafts. All authors read and approved the final version of this manuscript.

Funding The authors have not declared a specific grant for this research from any funding agency in the public, commercial or not-for-profit sectors.

Competing interests PAA: Consultant/Advisory Role: Bristol-Myers Squibb, RocheGenentech, Merck Sharp \& Dohme, Array, Novartis, Merck Serono, Pierre Fabre, Incyte, NewLink Genetics, Genmab, Medimmune, AstraZeneca, Syndax, SunPharma, Sanofi, Idera, Ultimovacs, Sandoz, Immunocore, 4SC, Alkermes, Italfarmaco, Nektar; Research Funds: Bristol-Myers Squibb, Roche-Genentech, Array; Travel support: MSD. FIA: Employee: Macrogenics, Inc. CGD: Consultant Fees: Agenus, AstraZeneca, Dendreon, Eli Lilly, Janssen, Merck, Pierre Fabre, Roche/Genetech; Ownership Interests: Compugen, Harpoon, Kleo; Patents/Royalties: AstraZeneca, Bristol-Myers Squibb, Janssen; Research Funding: Aduro Biotech, Bristol-Myers Squibb, Janssen. BAF: Co-Founder/Stock: UbiVac; Consulting/Research Support: Macrogenics, OncoSec, Shimadzu, Viralytics (Merck); Consulting (II-ON)/Research Support: Bristol-Myers Squibb; Consulting/Stock: PrimeVax; Research Support: NanoString, Quanterix; SAB: Argos, Bayer, CellDex, UltiVue; SAB/Institutional Research Support: AstraZeneca (Medlmmunne); SAB/Research Support: Akoya BioScience (Perkin Elmer), Definiens. SJO: Advisory Board: Biothera, Bristol-Myers Squibb, BionTech, Exicure, Immunsys, Merck; Consultant: Agenus, Biothera, Immunsys; Grants/ Research Support: Agenus, Amgen, Biothera, BMS, Exicure, Genocea, Incyte Merck, Ultimovacs, Viralytics; Speakers Bureau: Bristol-Myers Squibb. WJU: Advisory Board: Medlmmune, Bristol-Myers Squibb; Research Support/Contracted Work: BristolMyers Squibb; Research Support: Medlmmune. JMW: Consulting Fees: Western Oncolytics; Shareholder: MacroGenics, Inc. JSW: Consulting: Merck, Genentech, AstraZeneca, GSK, Novartis, Nektar, Medivation, Celldex, Incyte and EMD Serono; Advisory Board: Bristol-Myers Squibb, Celldex, CytoMx, Incyte, Biond, Protean, CV6 and Sellas; Equity: CytoMx, Biond and Altor; Patent/IP: Moffitt Cancer Center IPILIMUMAB biomarker, BioDesix PD-1 biomarker.

Patient consent for publication Not required.

Provenance and peer review Not commissioned; externally peer reviewed.

Open access This is an open access article distributed in accordance with the Creative Commons Attribution Non Commercial (CC BY-NC 4.0) license, which permits others to distribute, remix, adapt, build upon this work non-commercially, and license their derivative works on different terms, provided the original work is properly cited, appropriate credit is given, any changes made indicated, and the use is non-commercial. See http://creativecommons.org/licenses/by-nc/4.0/.

\section{ORCID iD}

Paolo Antonio Ascierto http://orcid.org/0000-0002-8322-475X

\section{REFERENCES}

1 Holshue ML, DeBolt C, Lindquist S, et al. First case of 2019 novel coronavirus in the United States. N Engl J Med 2020;382:929-36.

2 Fauci AS, Lane HC, Redfield RR. Covid-19 - Navigating the Uncharted. N Engl J Med 2020;382:1268-9.

3 Verity R, Okell LC, Dorigatti I, et al. Estimates of the severity of coronavirus disease 2019: a model-based analysis. Lancet Infect Dis 2020. doi:10.1016/S1473-3099(20)30243-7. [Epub ahead of print: 30 Mar 2020].

4 Conti P, Ronconi G, Caraffa A, et al. Induction of pro-inflammatory cytokines (IL-1 and IL-6) and lung inflammation by COVID-19: antiinflammatory strategies. J Biol Regul Homeost Agents 2020;34. 
5 Mo P, Xing Y, Xiao Y, et al. Clinical characteristics of refractory COVID-19 pneumonia in Wuhan, China. Clin Infect Dis 2020.

6 Qin C, Zhou L, Hu Z, et al. Dysregulation of immune response in patients with COVID-19 in Wuhan, China. Clin Infect Dis 2020. doi:10.1093/cid/ciaa248. [Epub ahead of print: 12 Mar 2020].

7 Wang Z, Yang B, Li Q, et al. Clinical features of 69 cases with coronavirus disease 2019 in Wuhan, China. Clin Infect Dis 2020 doi:10.1093/cid/ciaa272. [Epub ahead of print: 16 Mar 2020].

8 Chen G, Wu D, Guo W, et al. Clinical and immunological features of severe and moderate coronavirus disease 2019. J Clin Invest 2020;12.

9 Tian S, Hu W, Niu L, et al. Pulmonary pathology of early-phase 2019 novel coronavirus (COVID-19) pneumonia in two patients with lung cancer. J Thorac Oncol 2020.

10 Xu Z, Shi L, Wang Y, et al. Pathological findings of COVID-19 associated with acute respiratory distress syndrome. Lancet Respir Med 2020;8:420-2.

11 Tanaka T, Narazaki M, Kishimoto T. II-6 in inflammation, immunity, and disease. Cold Spring Harb Perspect Biol 2014;6:a016295.

12 Abboud R, Keller J, Slade M, et al. Severe Cytokine-Release syndrome after T Cell-Replete peripheral blood haploidentical donor transplantation is associated with poor survival and anti-IL-6 therapy is safe and well tolerated. Biol Blood Marrow Transplant 2016;22:1851-60.

13 Kotch C, Barrett D, Teachey DT. Tocilizumab for the treatment of chimeric antigen receptor T cell-induced cytokine release syndrome. Expert Rev Clin Immunol 2019;15:813-22.

14 Maude SL, Barrett D, Teachey DT, et al. Managing cytokine release syndrome associated with novel T cell-engaging therapies. Cancer J 2014;20:119-22.

15 Ascierto PA. SITC Statement on anti-IL-6/IL-6R for COVID-19 - Society for Immunotherapy of Cancer (SITC), 2020. Available: https://www.sitcancer.org/research/covid-19-resources/il-6editorial

16 Lai C-C, Liu YH, Wang C-Y, et al. Asymptomatic carrier state, acute respiratory disease, and pneumonia due to severe acute respiratory syndrome coronavirus 2 (SARS-CoV-2): facts and myths. J Microbiol Immunol Infect 2020.

17 Rodriguez-Morales AJ, Cardona-Ospina JA, Gutiérrez-Ocampo $\mathrm{E}$, et al. Clinical, laboratory and imaging features of COVID-19: a systematic review and meta-analysis. Travel Med Infect Dis 2020;101623.

18 Yang X, Yu Y, Xu J. Correction to Lancet Respir Med 2020.

19 Qian G-Q, Yang N-B, Ding F, et al. Epidemiologic and clinical characteristics of 91 hospitalized patients with COVID-19 in Zhejiang, China: a retrospective, multi-centre case series. QJM 2020. doi:10.1093/qjmed/hcaa089. [Epub ahead of print: 17 Mar 2020].

20 Zhang H, Zhou P, Wei Y, et al. Histopathologic changes and SARSCoV-2 immunostaining in the lung of a patient with COVID-19. Ann Intern Med 2020

21 Zhou F, Yu T, Du R, et al. Clinical course and risk factors for mortality of adult inpatients with COVID-19 in Wuhan, China: a retrospective cohort study. Lancet 2020;395:1054-62.

22 Huang C, Wang Y, Li X, et al. Clinical features of patients infected with 2019 novel coronavirus in Wuhan, China. The Lancet 2020;395:497-506.10.1016/S0140-6736(20)30183-5

23 La Rosée P. Treatment of hemophagocytic lymphohistiocytosis in adults. Hematology Am Soc Hematol Educ Program 2015;2015:190-6.

24 Tamamyan GN, Kantarjian HM, Ning J, et al. MalignancyAssociated hemophagocytic lymphohistiocytosis in adults: relation to hemophagocytosis, characteristics, and outcomes. Cancer 2016:122:2857-66.

25 Ruan Q, Yang K, Wang W, et al. Clinical predictors of mortality due to COVID-19 based on an analysis of data of 150 patients from Wuhan, China. Intensive Care Med 2020.

26 F S. Worst-Case estimates for U.S. coronavirus deaths. New York Times, 2020. (2020/03/13)

27 Ranney ML, Griffeth V, Jha AK. Critical supply shortages - the need for ventilators and personal protective equipment during the Covid-19 pandemic. N Engl J Med 2020.

28 Brudno JN, Kochenderfer JN. Toxicities of chimeric antigen receptor T cells: recognition and management. Blood 2016;127:3321-30.

29 Neelapu SS. Managing the toxicities of car T-cell therapy. Hematol Oncol 2019;37:48-52.

30 Santomasso B, Bachier C, Westin J, et al. The other side of car T-cell therapy: cytokine release syndrome, neurologic toxicity, and financial burden. Am Soc Clin Oncol Educ Book 2019;39:433-44.

31 Teachey DT, Lacey SF, Shaw PA, et al. Identification of predictive biomarkers for cytokine release syndrome after chimeric antigen receptor T-cell therapy for acute lymphoblastic leukemia. Cancer Discov 2016;6:664-79.

32 Xea X. Effective treatment of severe COVID19 patients with tocilizumab. Chinaxiv 2020.

33 Ascierto PA. Personal communication 2020.

34 COmmission $\mathrm{CNH}$. Chinese clinical guidance for COVID-19 pneumonia diagnosis and treatment, 2020. Available: http://kjfy. meetingchina.org $/ \mathrm{msite} / \mathrm{news} / \mathrm{show} / \mathrm{cn} / 3337$.html

35 FDA U. Coronavirus (COVID-19) supply chain update |FDA 2020.

36 Zhang L, Zhu F, Xie L, et al. Clinical characteristics of COVID19-infected cancer patients: a retrospective case study in three hospitals within Wuhan, China. Ann Oncol 2020. doi:10.1016/j. annonc.2020.03.296. [Epub ahead of print: 26 Mar 2020].

37 Crestani B, Cornillet P, Dehoux M, et al. Alveolar type II epithelial cells produce interleukin- 6 in vitro and in vivo. Regulation by alveolar macrophage secretory products. $J$ Clin Invest 1994:94:731-40.

38 Hallstrand TS, Hackett TL, Altemeier WA, et al. Airway epithelial regulation of pulmonary immune homeostasis and inflammation. Clinical Immunology 2014;151:1-15.

39 Hunter CA, Jones SA. II-6 as a keystone cytokine in health and disease. Nat Immunol 2015:16:448-57.

40 Oda S, Hirasawa $H$, Shiga $H$, et al. Sequential measurement of IL-6 blood levels in patients with systemic inflammatory response syndrome (SIRS)/sepsis. Cytokine 2005;29:169-75.

41 Luo Y, Zheng SG. Hall of fame among pro-inflammatory cytokines: interleukin-6 gene and its transcriptional regulation mechanisms. Front Immunol 2016;7:604.

42 Yoshikawa T, Hill T, Li K, et al. Severe acute respiratory syndrome (SARS) coronavirus-induced lung epithelial cytokines exacerbate SARS pathogenesis by modulating intrinsic functions of monocytederived macrophages and dendritic cells. J Virol 2009;83:3039-48.

43 Wang W, Ye L, Ye L, et al. Up-Regulation of IL-6 and TNF-alpha induced by SARS-coronavirus spike protein in murine macrophages via NF-kappaB pathway. Virus Res 2007;128:1-8.

44 Uciechowski P, Dempke WCM. Interleukin-6: a Masterplayer in the cytokine network. Oncology 2020:98:131-7.

45 Wolf J, Rose-John S, Garbers C. Interleukin-6 and its receptors: a highly regulated and dynamic system. Cytokine 2014;70:11-20.

46 Schumacher N, Meyer D, Mauermann A, et al. Shedding of endogenous interleukin-6 receptor (IL-6R) is governed by a disintegrin and metalloproteinase (ADAM) proteases while a fulllength IL-6R isoform localizes to circulating microvesicles. $J$ Biol Chem 2015;290:26059-71.

47 Schumacher N, Rose-John S. Adam17 activity and IL-6 transsignaling in inflammation and cancer. Cancers 2019;11:1736.

48 Sansone P, Bromberg J. Targeting the interleukin-6/Jak/stat pathway in human malignancies. JCO 2012;30:1005-14.

49 Bharadwaj U, Kasembeli MM, Robinson P, et al. Targeting Janus kinases and signal transducer and activator of transcription 3 to treat inflammation, fibrosis, and cancer: rationale, progress, and caution. Pharmacol Rev 2020;72:486-526.

50 Das R, Guan P, Sprague L, et al. Janus kinase inhibition lessens inflammation and ameliorates disease in murine models of hemophagocytic lymphohistiocytosis. Blood 2016;127:1666-75.

51 Ahmed A, Merrill SA, Alsawah F, et al. Ruxolitinib in adult patients with secondary haemophagocytic lymphohistiocytosis: an openlabel, single-centre, pilot trial. Lancet Haematol 2019;6:e630-7.

52 Kenderian SS, Ruella M, Shestova O, et al. Ruxolitinib prevents cytokine release syndrome after car T-cell therapy without impairing the anti-tumor effect in a xenograft model. Biology of Blood and Marrow Transplantation 2017;23:S19-20.

53 Novartis. Novartis announces plan to initiate clinical study of Jakavi ${ }^{\circledR}$ in severe COVID-19 patients and establish international compassionate use program | Novartis: @novartis, 2020. Available: https://www.novartis.com/news/media-releases/ novartis-announces-plan-initiate-clinical-study-jakavi-severecovid-19-patients-and-establish-international-compassionateuse-program

54 Schwartz DM, Kanno Y, Villarino A, et al. Jak inhibition as a therapeutic strategy for immune and inflammatory diseases. Nat Rev Drug Discov 2017;16:843-62.

55 O'Shea JJ, Kontzias A, Yamaoka K, et al. Janus kinase inhibitors in autoimmune diseases. Ann Rheum Dis 2013;72:ii111-5.

56 Goldbach-Mansky R. Immunology in clinic review series; focus on autoinflammatory diseases: update on monogenic autoinflammatory diseases: the role of interleukin (IL)-1 and an emerging role for cytokines beyond IL-1. Clin Exp Immunol 2012;167:391-404.

57 Weber A, Wasiliew P, Kracht M. Interleukin-1 (IL-1) pathway. Science Signaling 2010;3: $\mathrm{cm} 1$. 
58 Dinarello CA, Simon A, van der Meer JWM. Treating inflammation by blocking interleukin-1 in a broad spectrum of diseases. Nat Rev Drug Discov 2012;11:633-52.

59 Santarlasci V, Cosmi L, Maggi L, et al. II-1 and T helper immune responses. Front Immunol 2013;4:182.

60 Tisoncik JR, Korth MJ, Simmons CP, et al. Into the eye of the cytokine storm. Microbiology and Molecular Biology Reviews 2012;76:16-32.

61 Wu D, Yang XO. Th17 responses in cytokine storm of COVID-19: an emerging target of JAK2 inhibitor fedratinib. J Microbiol Immunol Infect 2020.

62 Mahallawi WH, Khabour OF, Zhang Q, et al. Mers-Cov infection in humans is associated with a pro-inflammatory Th1 and Th17 cytokine profile. Cytokine 2018;104:8-13

63 Jesus AA, Goldbach-Mansky R. II-1 blockade in autoinflammatory syndromes. Annu Rev Med 2014;65:223-44.

64 Dinarello CA. Interleukin-1 in the pathogenesis and treatment of inflammatory diseases. Blood 2011;117:3720-32.

65 Arend WP, Malyak M, Guthridge CJ, et al. Interleukin-1 receptor antagonist: role in biology. Annu Rev Immunol 1998;16:27-55.

66 Garlanda C, Riva F, Bonavita E, et al. Decoys and Regulatory "Receptors" of the IL-1/Toll-Like Receptor Superfamily. Front Immunol 2013;4:180.

67 Fisher CJ, Slotman GJ, Opal SM, et al. Initial evaluation of human recombinant interleukin-1 receptor antagonist in the treatment of sepsis syndrome: a randomized, open-label, placebocontrolled multicenter trial. Crit Care Med 1994;22:12-21.

68 Fisher CJ, Dhainaut JF, Opal SM, et al. Recombinant human interleukin 1 receptor antagonist in the treatment of patients with sepsis syndrome. results from a randomized, double-blind, placebo-controlled trial. phase III rhIL-1ra sepsis syndrome Study Group. JAMA 1994;271:1836-43.

69 Opal SM, Fisher CJ, Dhainaut JF, et al. Confirmatory interleukin-1 receptor antagonist trial in severe sepsis: a phase III, randomized, double-blind, placebo-controlled, multicenter trial. The interleukin-1 receptor antagonist sepsis investigator group. Crit Care Med 1997:25:1115-24

70 Shakoory B, Carcillo JA, Chatham WW, et al. Interleukin-1 receptor blockade is associated with reduced mortality in sepsis patients with features of macrophage activation syndrome: reanalysis of a prior phase III trial. Crit Care Med 2016;44:275-81.

71 Furst DE. Anakinra: review of recombinant human interleukinreceptor antagonist in the treatment of rheumatoid arthritis. Clin Ther 2004;26:1960-75.

72 Norelli M, Camisa B, Barbiera G, et al. Monocyte-Derived IL-1 and IL-6 are differentially required for cytokine-release syndrome and neurotoxicity due to CAR T cells. Nat Med 2018;24:739-48.

73 Alejo A, Ruiz-Argüello MB, Pontejo SM, et al. Chemokines cooperate with TNF to provide protective anti-viral immunity and to enhance inflammation. Nat Commun 2018;9:1790.

74 Shrestha B, Zhang B, Purtha WE, et al. Tumor necrosis factor alpha protects against lethal West Nile virus infection by promoting trafficking of mononuclear leukocytes into the central nervous system. J Virol 2008;82:8956-64.

75 Seo SH, Webster RG. Tumor necrosis factor alpha exerts powerful anti-influenza virus effects in lung epithelial cells. J Virol 2002;76:1071-6.

76 Sinha P, Ware LB. Selective tumour necrosis factor receptor-1 inhibition in acute lung injury: a new hope or a false dawn? Thorax 2018;73:699-701.

77 Mukhopadhyay S, Hoidal JR, Mukherjee TK. Role of TNF $\alpha$ in pulmonary pathophysiology. Respir Res 2006;7:125.

78 Locksley RM, Killeen N, Lenardo MJ. The TNF and TNF receptor superfamilies: integrating mammalian biology. Cell 2001;104:487-501.

79 Aggarwal BB. Signalling pathways of the TNF superfamily: a double-edged sword. Nat Rev Immunol 2003;3:745-56.

80 Malaviya R, Laskin JD, Laskin DL. Anti-TNF $\alpha$ therapy in inflammatory lung diseases. Pharmacol Ther 2017:180:90-8.

81 Abraham E, Wunderink R, Silverman $\mathrm{H}$, et al. Efficacy and safety of monoclonal antibody to human tumor necrosis factor alpha in patients with sepsis syndrome. A randomized, controlled, doubleblind, multicenter clinical trial. TNF-alpha mAb sepsis Study Group. JAMA 1995;273:934-41.

82 Abraham E, Anzueto A, Gutierrez G, et al. Double-Blind randomised controlled trial of monoclonal antibody to human tumour necrosis factor in treatment of septic shock. The Lancet 1998;351:929-33.

83 Barnes PJ. Unexpected failure of Anti-Tumor necrosis factor therapy in chronic obstructive pulmonary disease. Am J Respir Crit Care Med 2007:175:866-7.
84 Fu B. Personal communication 2020.

85 Lee DW, Gardner R, Porter DL, et al. Current concepts in the diagnosis and management of cytokine release syndrome. Blood 2014;124:188-95.

86 Flammiger A, Fiedler W, Bacher U, et al. Critical imbalance of TNF-A and soluble TNF receptor 1 in a patient with macrophage activation syndrome: potential implications for diagnostics and treatment. Acta Haematol 2012;128:69-72.

87 De Andrea M, Ravera R, Gioia D, et al. The interferon system: an overview. Eur J Paediatr Neurol 2002;6 Suppl A:A41-6.

88 Farrar MA, Schreiber RD. The molecular cell biology of interferongamma and its receptor. Annu Rev Immunol 1993;11:571-611.

89 Bach EA, Aguet M, Schreiber RD. The IFN gamma receptor: a paradigm for cytokine receptor signaling. Annu Rev Immunol 1997:15:563-91.

90 Shtrichman R, Samuel CE. The role of gamma interferon in antimicrobial immunity. Curr Opin Microbiol 2001;4:251-9.

91 Skurkovich B, Skurkovich S. Anti-interferon-gamma antibodies in the treatment of autoimmune diseases. Curr Opin Mol Ther 2003;5:52-7.

92 Harden JL, Johnson-Huang LM, Chamian MF, et al. Humanized anti-IFN- $\gamma$ (HuZAF) in the treatment of psoriasis. J Allergy Clin Immunol 2015;135:553-6.

93 Skurkovich B, Skurkovich S. Inhibition of IFN-gamma as a method of treatment of various autoimmune diseases, including skin diseases. Ernst Schering Res Found Workshop 2006;56:1-27.

94 Pedersen SF, Ho Y-C. SARS-CoV-2: a storm is raging. $J$ Clin Invest 2020. doi:10.1172/JCl137647. [Epub ahead of print: 13 Apr 2020].

95 Biondillo DE, Konicek SA, Iwamoto GK. Interferon-Gamma regulation of interleukin 6 in monocytic cells. Am J Physiol Lung Cell Mol Physiol 1994;267:L564-8.

96 Huang K-J, Su I-J, Theron M, et al. An interferon-?-related cytokine storm in SARS patients. J Med Virol 2005;75:185-94.

97 Liu B, Bao L, Wang L, et al. Anti-IFN- $\gamma$ therapy alleviates acute lung injury induced by severe influenza $A(\mathrm{H} 1 \mathrm{~N} 1)$ pdm09 infection in mice. J Microbiol Immunol Infect 2019.10.1016/j. jmii.2019.07.009

98 Sobi to initiate a clinical study to evaluate whether anakinra and emapalumab may relieve complications associated with severe COVID-19 disease [press release] 2020.

99 SOBI. GamifantÂ® (emapalumab-lzsg) prescribing information, 2020. Available: https://www.gamifant.com/result.php

100 Han S, Mallampalli RK. The acute respiratory distress syndrome: from mechanism to translation. J.i. 2015;194:855-60.

101 Lotfi N, Thome R, Rezaei N, et al. Roles of GM-CSF in the pathogenesis of autoimmune diseases: an update. Front Immunol 2019;10.

102 Sachdeva M, Duchateau P, Depil S, et al. Granulocyte-Macrophage colony-stimulating factor inactivation in car T-cells prevents monocyte-dependent release of key cytokine release syndrome mediators. J Biol Chem 2019;294:5430-7.

103 Sterner RM, Sakemura R, Cox MJ, et al. Gm-Csf inhibition reduces cytokine release syndrome and neuroinflammation but enhances CAR-T cell function in xenografts. Blood 2019;133:697-709.

104 Zhou Y, Fu B, Zheng X, et al. Pathogenic T cells and inflammatory monocytes incite inflammatory storm in severe COVID-19 patients. National Science Review 2020

105 FDA Approves Emergency IND Use of Humanigen's Lenzilumab For Compassionate Use In COVID-19 Patients [press release]. @ap, 2020-04-02 2020

106 I-Mab Biopharma Announces development of TJM2 to treat cytokine release syndrome associated with severe and critically-ill patients with coronavirus disease (COVID-19) 2020.

107 Roivant Announces Development of Anti-GM-CSF Monoclonal Antibody to Prevent and Treat Acute Respiratory Distress Syndrome (ARDS) in Patients with COVID-19 - Roivant Sciences 2020.

108 Teunissen MB, Koomen CW, de Waal Malefyt R, et al. Interleukin-17 and interferon-gamma synergize in the enhancement of proinflammatory cytokine production by human keratinocytes. $J$ Invest Dermatol 1998;111:645-9.

109 Schön MP, Erpenbeck L. The Interleukin-23/Interleukin-17 axis links adaptive and innate immunity in psoriasis. Front Immunol 2018:9:1323.

110 Bai F, Li GG, Liu Q, et al. Short-Term efficacy and safety of IL-17, IL$12 / 23$, and IL-23 inhibitors Brodalumab, Secukinumab, ixekizumab, ustekinumab, Guselkumab, Tildrakizumab, and Risankizumab for the treatment of moderate to severe plaque psoriasis: a systematic review and network meta-analysis of randomized controlled trials. $J$ Immunol Res 2019;2019:1-25. 